\title{
IMPROVEMENT AND ESTIMATION OF ORALLY DISINTEGRATING TABLETS CONTAINING PILOCARPINE 2-HYDROXY PROPYL $\beta$-CYCLODEXTRIN INCLUSION COMPLEX BY RESPONSE SURFACE METHODOLOGY
}

\author{
JOGABRATA TRIPATHY ${ }^{1}$, SUBHASHREE SAHOO ${ }^{1}$, AFRASIM MOIN ${ }^{2}$, SIDDARAMAIAH ${ }^{3}$, D. V. GOWDA ${ }^{*}$
}

${ }^{1 *}$ Department of Pharmaceutics, JSS College of Pharmacy, JSS Academy of Higher Education and Research, S. S. Nagara, Mysuru 570015, Karnataka, India, ${ }^{2}$ Department of Pharmaceutics, College of Pharmacy, University of Hail, PO Box 2440, Hail, Saudi Arabia, ${ }^{3}$ Department of Polymer Science and Technology, S. J. College of Engineering, JSS Science and Technology University, Mysuru 570006, Karnataka, India "Email: dvgowda@jssuni.edu.in

Received: 18 Nov 2020, Revised and Accepted: 18 Jan 2021

\begin{abstract}
Objective: The study aimed to develop and evaluate an orally disintegrating tablet that contains pilocarpine and 2-hydroxy propyl $\beta$-cyclodextrin as an inclusion complex that is prepared by lyophilization used for treatment for dry mouth. Pilocarpine is utilized to treat dry mouth disorder. The inclusion complex lowers the taste of pilocarpine through the oral mucosa by the use of 2-hydroxy propyl $\beta$-cyclodextrin.

Methods: The in vitro release from the insertion complex is also been studied. The parameters like differential scanning calorimetry (DSC), Fourier transformer infrared spectroscopy (FTIR), X-ray diffraction (XRD), and morphological study have been evaluated. The design of an experiment is carried out based on the concentration of croscarmellose sodium (CCS) and microcrystalline cellulose (MCC). Evaluation of the prepared orally disintegrating tablets have been carried out by different test methods like weight variation, thickness, drug content, disintegration, and in vitro dissolution study.

Results: Orally disintegrating tablets are studied by utilizing the immediate pressure technique. Pilocarpine indicates the anhydrous crystalline medication, displaying sharp endothermic top at $120.2^{\circ} \mathrm{C}$, bend of 2 -HP $\beta C D$ demonstrates an exceptionally wide endothermal wonder among $55-$ $100^{\circ} \mathrm{C}$ for DSC. In pilocarpine spectra, characteristic band of aromatic C-H stretch at $3277 \mathrm{~cm}^{-1}, \mathrm{C}=\mathrm{C}$ stretching at $1608 \mathrm{~cm}^{-1}$, C-N stretching at 1445 $\mathrm{cm}^{-1}$ and methoxy $\left(\mathrm{CH}_{3}-\mathrm{O}-\right)$ stretch at $2921 \mathrm{~cm}^{-1}$ was observed. The investigation shows that tablet hardness of $4.3 \mathrm{~N}$, breaking downtime of $12 \mathrm{sec}$ and mean disintegration time is $1.562 \mathrm{~min}$.
\end{abstract}

Conclusion: The different diluents and super disintegrating have been applied for the quick elevation of dry mouth that helps us for patient compliance.

Keywords: Pilocarpine, 2-hydroxy propyl $\beta$-cyclodextrin, Orally disintegrating tablets

(c) 2021 The Authors. Published by Innovare Academic Sciences Pvt Ltd. This is an open access article under the CC BY license (https://creativecommons.org/licenses/by/4.0/) DOI: https://dx.doi.org/10.22159/ijap.2021v13i2.40292. Journal homepage: https://innovareacademics.in/journals/index.php/ijap

\section{INTRODUCTION}

Orally disintegrating tablets are normally compelled using a direct compaction technique as this is the easiest and most money-making production process. Choosing excipients is considered as chief limitations establishing the property of an orally disintegrating tablet. Disintegrant, binder, glider, lubricant, sweeteners, and masking agent for taste were employed for the formulation [1]. Dissolving in diluents affects the mechanism of dissolutions and break down of formulation. Disintegrant and diluents concentration has a strong impact on the time of disintegration and the mechanism of dissolution. Tablet breaking time optimization can be reached by determining the optimal disintegrant and diluents amounts $[2,3]$. The breakdown period is negatively proportional to the breakdown rate below critical absorption and more than this breakdown period, it resides mostly persistent. Hence, their attributes will be affected by modifying the proportion and centralizations of diluents and breaks down in orally disintegrating tablets articulation [4]. Organic cyclodextrin cyclic oligosaccharide with 6-( $\alpha$-cyclodextrin), 7-( $\beta$ cyclodextrin) either 8-glucopyranose unit attached to the macrocycle by $\alpha-14$-glycoside bonds. It has an outer layer of hydrophilic and a hydrophobic cavity [5].

After complexation, the physicochemical property of the visitor atom involved is reform and the insertion complexes were used to increase stability, solubility, rate of dissolution, and bioavailability. Through encasing the utilitarian gathering liable for the severe taste inside the depression, they can likewise diminish the unpleasant taste of very harsh items [6].

Pilocarpine is a characteristic compound got from Pilocarpus jaborandi, a South American shrub. This plant alkaloid is a cholinergic parasympathomimetic agonist that ties to muscarinicM3 receptors and can trigger pharmacological smooth muscle compression in people and incitement of different exocrine glands [7]. Pilocarpine hydrochloride tablets are shown for analysis of radiation-initiated dry mouth.

Pilocarpine HCl-2-Hydroxy Propyl $\beta$-cyclodextrin insertion composite depending upon orally disintegrating tablets was suggested in this present investigation. The insertion complex limits the harsh taste of Pilocarpine $\mathrm{HCl}$ in the plan while upgrading the ingestion penetrability through the oral mucosa [8]. Oral mucosa is where orally disintegrating tablets formulations are utilized. These perplexing acknowledgments based on orally disintegrating tablets are perfect for populaces confronting trouble gulping regular Pilocarpine $\mathrm{HCl}$ unpleasant tasting tablets [9].

\section{MATERIALS AND METHODS}

\section{Materials}

Pilocarpine Hydrochloride was purchased from Merck Specialist Pvt. Ltd., Mumbai, India. The 2-Hydroxy Propyl $\beta$-cyclodextrin (2$\mathrm{HP} \beta C D$ ) is procured from Hi-Media Lab. Pvt. Ltd., India, Mannitol is obtained from SRL Pvt. Ltd., Bombay, India. Croscarmellose sodium (CCS) and microcrystalline cellulose (MCC) were obtained from LOBA Chemical Pvt. Ltd., Mumbai, India. Sodium stearyl fumarate was supplied from Merck Specialist Pvt. Ltd., Mumbai, India. Other reagents and solvents were utilized for logical evaluation. Deionized water was used throughout the investigations.

\section{Methods}

Phase solubility study

Based on the procedure reported before by Higuchi and Connors, 1965 , the stage solvency study was carried out. The graph of stage 
solvency was procured in the water at $\mathrm{pH}$ 7. A surplus of Pilocarpine $(200 \mathrm{mg})$ was applied in screw-cap glass vials consisting of an expanded sum of 2-HP $\beta C D$ (range $0-0.025 \mathrm{M}$ ) to $10 \mathrm{ml}$ of liquid. The vials are installed in a thermo-shaker and continuously shaken at $500 \mathrm{rpm}$ at $37 \pm 0.5{ }^{\circ} \mathrm{C}$. After meeting equilibrium, the suspensions were stirred for $48 \mathrm{~h}$. The sample solutions were filtered and adequately diluted via a $0.20 \mu \mathrm{m}$ membrane filter after equilibrium is achieved. The solubilized pilocarpine was calculated by an HPLC method described below in different concentrations of the 2-HP $\beta C D$ solution and triplicate tests were performed [10]. Previous findings showed that 2-HP $\beta C D$ at the concentration used will not inquisitive the HPLC resolution. According to the formula, the stability constant $\left(\mathrm{K}_{\mathrm{s}}\right)$ was determined from the stage dissolvability figure, assuming 1:1 stoichiometry (because the slope is less than 1 ).

\section{Preparation of the inclusion complex}

Lyophilized insertion composite is composed of solubilizing the precise sums (molar ratio) of pilocarpine with 2-HP $\beta C D$ at ambient temperature $\left(27 \pm 1{ }^{\circ} \mathrm{C}\right)$ in deionized water. The resulting solution was frozen for $48 \mathrm{~h}$. at $-50^{\circ} \mathrm{C}$ and $0.03 \mathrm{Mbar}$ (MODULYO, Edwards UK). The insertion composite was triturated then passed by 60 mesh sieving instrument and reserved until further analysis was done in light-preserved desiccators. Also, the physical blend was set up via cautious blending of the precise rate (molar proportions) of pilocarpine and 2 -HP $\beta C D$ and parallel mixture inside the fired mortar (12 min).

\section{Differential scanning calorimetry (DSC)}

Estimation is done to determine unadulterated pilocarpine, unadulterated 2-HP $\beta C D, 1: 1$ corporal blend and 1:1 consideration complex was done utilizing a DSC-60 (SHIMADZU, Kyoto, Japan). The
DSC investigation considered adjustment with the pace of warmth consumed by pilocarpine in elaboration with 2-HP $\beta C D$ [11].

\section{Fourier transform infrared spectroscopy (FTIR)}

FTIR spectroscopy of unadulterated pilocarpine, unadulterated 2HP $\beta C D, 1: 1$ physical mixture, and 1:1 consideration complex was utilized by an FTIR-8400S spectrometer (SHIMADZU, Kyoto, Japan) outfitted with germanium precious stone. Spectroscopy accession is executed legitimately with granule tests by utilization with 63 sweeps at a goal of $2 \mathrm{~cm}^{-1}[12]$.

\section{Powder X-ray diffraction}

This is done by utilizing pilocarpine, 2-HP $\beta C D$, physical mixture, 1:1 consideration complex were gathered utilizing X-ray diffraction furnished with fast indicator and CuK $\alpha$ origin with a charge of $43 \mathrm{kV}$, and a current of $40 \mathrm{~mA}$. The unadulterated Pilocarpine, unadulterated 2-HP $\beta C D$, physical mixture, and 1:1 consideration complex were inspected utilizing Zeiss EVO LS 15, Smart SEM Germany. The sample is attached on a metal stub utilizing a two fold side and afterward by shower covering in space with a flimsy sheet at $0.6 \mathrm{kV}$ [13].

\section{Tablet compression of inclusion complex}

\section{Design of experiments}

The focal complex structure comprises a partial plan whose focal focuses that these are enlarged to a gathering of pivotal points, which results in the estimation of curvature. In a face-focused focal composite plan, star focuses are at the focal point of factorial structure focuses. Two factors, three levels face focused focal complex plan is utilized for the streamline of variables. Components are assessed with high levels, medium, and low $(+1,0$, and-1) [14].

Table 1: Factorial central composite design (CCD)

\begin{tabular}{|c|c|c|c|c|}
\hline Liberated variables & Formulation & Design level & & Coded level \\
\hline \multirow[t]{3}{*}{$\mathrm{CCS}, \mathrm{X}_{1}(\mathrm{mg})$} & A & 0 & low & -1 \\
\hline & & 6 & Medium & 0 \\
\hline & & 12 & high & 1 \\
\hline \multirow[t]{3}{*}{ MCC, $\mathrm{X}_{2}$ (mg) } & B & 0 & low & -1 \\
\hline & & 60 & Medium & 0 \\
\hline & & 120 & high & 1 \\
\hline
\end{tabular}

Note: CCS, $\mathrm{X}_{1}$-Diluent Croscarmellose sodium; MCC, $\mathrm{X}_{2}$-Superdisintegrant Microcrystalline cellulose; CCD-Central Composite Design

\section{Tablet manufacturing}

Pilocarpine-2-HP $\beta C D$ physical mixture is sieved with \#40 work strainer previous to blending. Different additives were precisely gauged and blended out and out in with Pilocarpine-2-HPßCD consideration complex for $15 \mathrm{~min}$. Sodium stearyl fumarate was mixed with the mix then greased up for $7 \mathrm{~min}$ additional in a blender. Tablets are packed with a solitary punching instrument utilizing $0.370 \mathrm{inch}$.

Table 2: Pilocarpine loaded ODT formulations

\begin{tabular}{ll}
\hline Ingredients & Weight (mg) \\
\hline Pilocarpine-2-HP $\beta$ CD complex & $12^{*}$ \\
Croscarmellose Sodium & $0 / 5 / 10$ \\
Microcrystalline Cellulose & $0 / 50 / 100$ \\
Sodium Stearyl Fumarate & 1.8 \\
Flavoring agent & 1.8 \\
Mannitol & q. S \\
\hline
\end{tabular}

Note: *Incorporation composite granule comparable with $10 \mathrm{mg}$ Pilocarpine; q. s= Quantity sufficient; 2-HP $\beta C D$-Hydroxyl propyl $\beta$ cyclodextrin; ODT-Oral disintegrating tablet

\section{Evaluation of prepared ODT's}

\section{Variation in weight}

Weight variety of all clumps of Oral Disintegrating Tablets (ODTs) is surveyed. 20 tablets from all bunch are separately gauged along with normal mass are accounted.

\section{Thickness}

Reweighed ten tablets from all groups are tried. A micrometer was utilized to gauge the normal thickness and standard deviation was accounted.

\section{Friability}

Twenty tablets of the formulation are gauged along with estimated in friabilator (Electro lab Mumbai India). Turn acceleration is set to $30 \mathrm{rpm}$ with $5 \mathrm{~min}$, and tablets are re-gauged. Rate friability is determined by utilizing the condition.

\section{Content of drug}

Three tablets are weighed independently for all clusters and squashed in an earthenware mortar. Precisely gauged amounts of amorphous tablets $(595 \mathrm{mg})$ are separated with $\mathrm{pH} 6.7$ phosphate cradles. The investigations are utilized thrice with normal qualities and standard deviations are accounted.

\section{Hardness}

All groups containing 10 tablets with concise mass are inspected for the hardness of tablets utilizing a hardness tester. The normal hardness and standard deviation for each bunch were accounted [15].

\section{Wetting time and water absorption ratio}

A tissue paper of size $14 \times 14 \mathrm{~cm}$ is collapsed two times and set in the watch glass ( $8 \mathrm{~cm}$ breadth) consisting of $5 \mathrm{ml}$ water. Tablet is set over the tissue paper and the time need for water to arrive at the top 
layer is considered to be wetting time. Investigations are done thrice. Water retention proportion (R) is resolved to utilize the accompanying condition [16]

\section{In vitro dissolution test}

ODT is assessed for dissolution conduct. Dissolution analysis is executed according to USP necessities with prompt discharge dose structures utilizing USP II mechanical assembly paddle technique [17]. Dissolution was completed in $900 \mathrm{ml}$ phosphate support pH 6.7 with $70 \mathrm{rpm}$ and $36.5 \pm 0.6^{\circ} \mathrm{C}$. Dissolution with $\mathrm{pH} 6.7$ is maintained, which reproduces $\mathrm{pH}$ states with salivation liquid [18].

\section{Statistical analysis and optimization}

The measurable mode in association with terms is determined to assess the impact of 2 factors $\left(\mathrm{X}_{1}\right.$ and $\left.\mathrm{X}_{2}\right)$ with reaction factors: hardness of tablet $\left(\mathrm{Y}_{1}\right)$, deterioration time $\left(\mathrm{Y}_{2}\right)$ also, mean disintegration time-MDT $\left(\mathrm{Y}_{3}\right)$. Polynomial models were produced for each reaction factor [19]. The investigation leads to a direct mode which is utilized for the decision of relationship among elements with reaction factors $\left(\mathrm{Y}_{1}\right)$ and quadratic models for deciding the connection among components and reaction factors $\left(\mathrm{Y}_{2}\right) /\left(\mathrm{Y}_{3}\right)$.

\section{RESULTS AND DISCUSSION}

\section{Phase solubility study}

Stage solvency graph is acquired at $37.5^{\circ} \mathrm{C}$ by plotting the obvious dissolvability of pilocarpine versus expanding grouping of 2hydroxy propyl $\beta$-cyclodextrin. It is seen that the solvency of pilocarpine from composite expanded straightly with a component of 2-HP $\beta C D$ fixation. The stage solvency profile (straight plot) was delegated AL type. These AL-type bends show the development of water solvent edifices among pilocarpine and $2-\mathrm{HP} \beta C D$ with a $1^{\text {st }}$ request reliance connection of 2-Hydroxy propyl $\beta$-cyclodextrin fixation [20]. This straight substrate-ligand connection with slant esteem under 1 proposed the development of first request solvent edifices, for example, the development of 1:1 stoichiometry consideration complex.

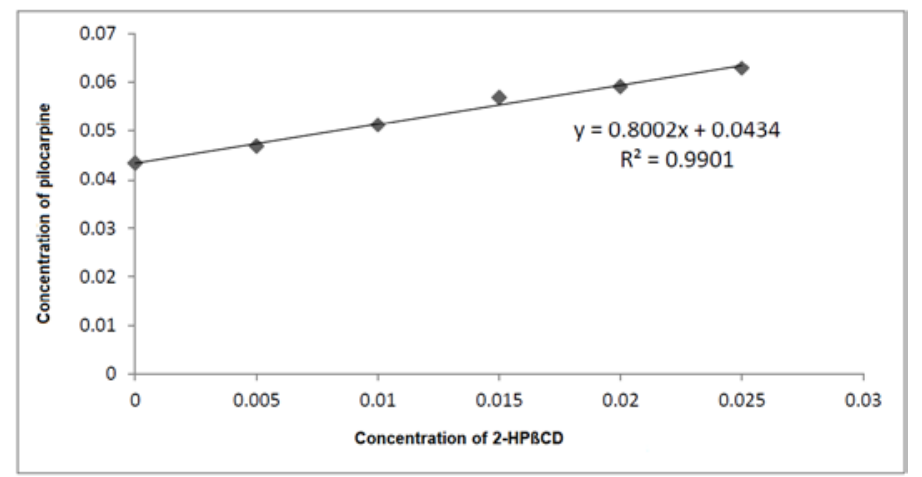

Fig. 1: Phase solubility for Pilocarpine 2-HPßCD insertion composite, ${ }^{*}$ mean \pm SD (n=3)

\section{Content of drug in insertion complex}

Real medication consisting of the corporal blend and lyophilized composite are analyzed. Results are accounted. As found in the table, both physical mixture with lyophilized composite demonstrated a decent understanding of hypothetical and real medication content. The standard deviation of the physical mixture was found to be $94.38 \pm 0.55$ $\%$ and the lyophilized mixture was found to be $95.48 \pm 0.97 \%$.

Table 3: Drug content in the inclusion complex (mean \pm SD)

\begin{tabular}{lll}
\hline Mixtures & Theoretical range & mean \pm SD* $^{*}$ \\
\hline Physical mixture & 100.0 & $94.38 \pm 0.55$ \\
Lyophilized mixture & 100.0 & $95.48 \pm 0.97$ \\
\hline
\end{tabular}

Note: *mean $\pm \mathrm{SD}(\mathrm{n}=3)$

\section{Characterization of inclusion complex}

\section{Differential scanning calorimetry}

Differential scanning calorimetry bends for Pilocarpine, 2hydroxypropyl $\beta$-cyclodextrin, physical mixture, and Lyophilized Pilocarpine-2-hydroxypropyl $\beta$-cyclodextrin in corporation composite considered is accounted [21]. Pilocarpine indicated the run-of-the-mill conduct of anhydrous crystalline medication, displaying a sharp endothermic top at $120.2{ }^{\circ} \mathrm{C}$, relating to liquefying purpose for medication. The DSC bend of 2-HP $\beta C D$ demonstrated an exceptionally wide endothermal wonder among $55-100{ }^{\circ} \mathrm{C}$, because of the arrival of water atoms. The corporal blend of pilocarpine and 2-hydroxy propyl $\beta$-cyclodextrin indicates an endothermic top, $125{ }^{\circ} \mathrm{C}$. The physical mixture of pilocarpine with 2-HP $\beta C D$ showed the endothermic peak at $120{ }^{\circ} \mathrm{C}$ but with a decreased enthalpy of reaction. The complete disappearance of the pilocarpine endothermic peak was observed for lyophilized pilocarpine 2-HPßCD inclusion complex indicating the encapsulation of drug molecule inside the cavity or formation of the amorphous complex or both.

\section{Fourier transforms infrared spectroscopy}

Fourier transform infrared spectra explored utilitarian gatherings with pilocarpine engaged with the complexation gives strong proof of complex development [22]. The FTIR spectra of every one of the examples are displayed in the figure. In pilocarpine spectra, the characteristic band of aromatic $\mathrm{C}-\mathrm{H}$ stretch at $3277 \mathrm{~cm}^{-1}, \mathrm{C}=\mathrm{C}$ stretching at $1608 \mathrm{~cm}^{-1}, \mathrm{C}-\mathrm{N}$ stretching at $1445 \mathrm{~cm}^{-1}$,and methoxy (CH3-0-) stretch at $2921 \mathrm{~cm}^{-1}$ was observed and used to determine the interaction between $2 \mathrm{HP} \beta \mathrm{CD}$ and pilocarpine in the solid-state. FTIR spectra for 2-HP $\beta C D$ shows $0-\mathrm{H}$ stretching at $3290 \mathrm{~cm}^{-1}$. Spectra for both the physical mixture and lyophilized complex did not show new peaks indicating that no chemical bonds were created in the formed complex; however, shifting of the characteristic peak at $1445 \mathrm{~cm}^{-1}$ towards a lower wavenumber $\left(1358 \mathrm{~cm}^{-1}\right)$ in lyophilized the inclusion complex was seen. This suggests the formation of hydrogen bonds between the amino group of pilocarpine and the hydroxyl groups of the cyclodextrin cavity. The amino group of pilocarpine is responsible for the bitter taste of the drug. From these findings, it can be postulated that the complexation of the bitter-tasting amino functional group inside the cavity drastically reduces the bitterness of pilocarpine. In the physical mixture, characteristic peaks of pilocarpine were still detected with low intensity.

\section{$\mathrm{X}$-ray diffraction}

Powder X-ray diffraction design is made with unadulterated pilocarpine displayed a few diffraction tops demonstrating the crystalline idea of the medication as appeared in fig. 4. Conversely, 2-HP $\beta C D$ was available in a nebulous structure. The 1:1 physical blend additionally displayed a common diffraction design yet force contrasted with the diffraction design for the unadulterated medication. The 1:1 physical mixture also 
exhibited a typical crystalline diffraction pattern but of less intensity compared to the diffraction pattern for the pure drug. This confirmed the presence of pilocarpine in its crystalline form in the 1:1 physical mixture and no inclusion complex was formed. It also showed a weak interaction between drug and cyclodextrin in the physical mixture, confirming the DSC results. Pilocarpine-2-HPßCD inclusion complex displayed diffuse diffraction patterns (identical to that of 2-HP $\beta C D$ without drug peaks), suggesting the entirely amorphous nature of pilocarpine in 1:1 lyophilized complex [22].

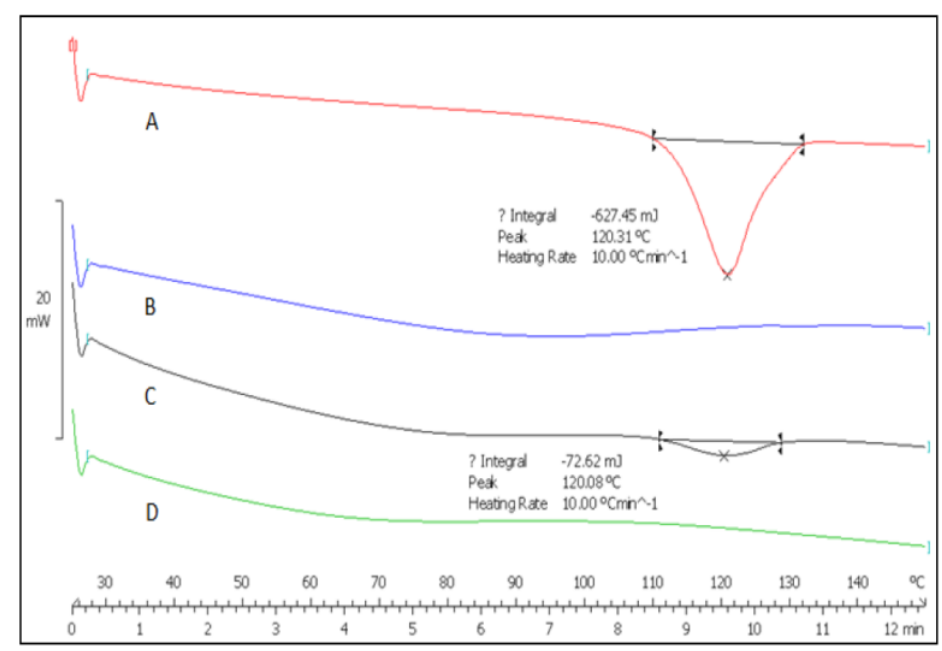

Fig. 2: Differential scanning calorimetry thermograms for Pilocarpine (A), 2-HPßCD (B), 1:1 mixture, (C) and 1:1 lyophilized (D) Pilocarpine 2-HP $\beta C D$ insertion composite $* 2-H P \beta C D=$ Hydroxyl propyl $\beta$ cyclodextrin

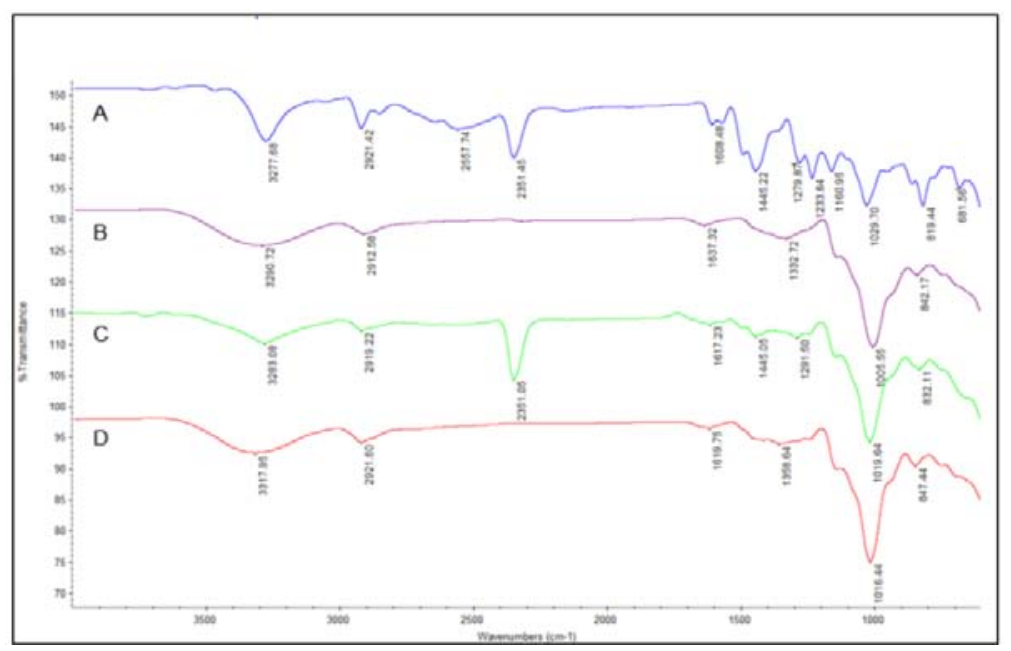

Fig. 3: FTIR spectra for pure Pilocarpine (A), pure 2-HPßCD (B), and physical, Mixture (C) and lyophilized (D) Pilocarpine 2-HPßCD insertion composite, ${ }^{*} 2-\mathrm{HP} \beta C D=$ Hydroxyl propyl $\beta$ cyclodextrin

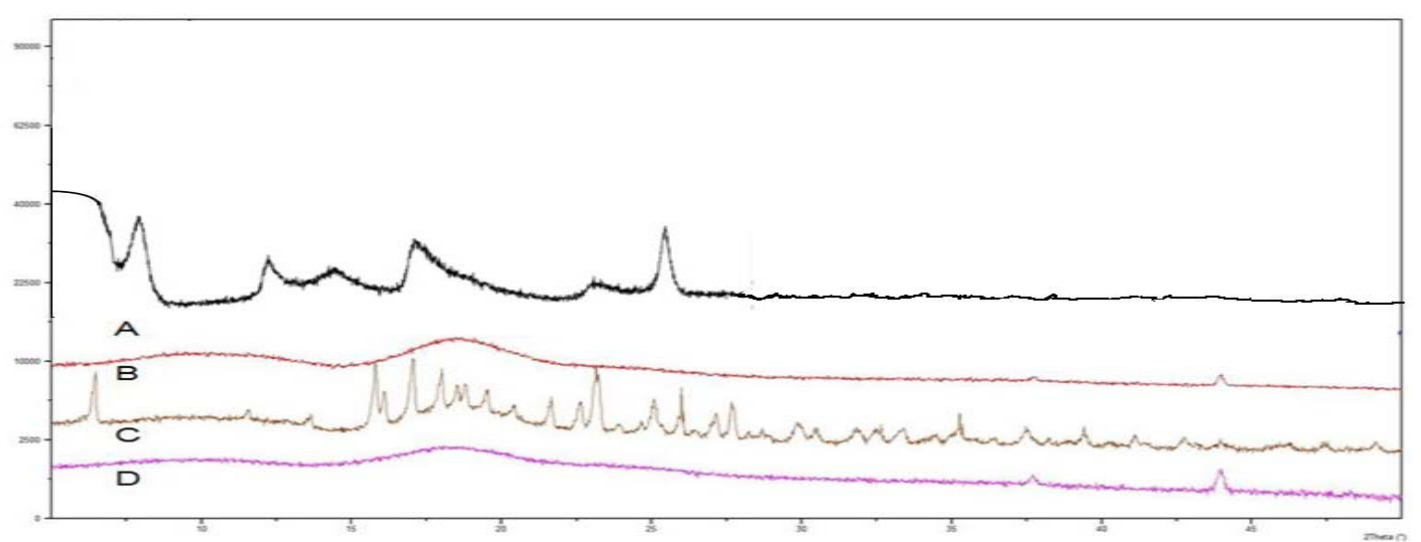

Fig. 4: XRD of pilocarpine (A), 2-HPßCD (B) physical mixture(C) and Lyophilized Pilocarpine2-HP $\beta C D$ (D) insertion composite, *2-HPßCD= Hydroxyl propyl $\beta$ cyclodextrin 


\section{Dissolution study}

Dissolution profile was done for unadulterated Pilocarpine, corporal blend, and lyophilized blend and every one of the details dissolved around 90\% of the Pilocarpine shortly [23]. Dissolution parameters, its productivity following $10 \mathrm{~min}$ (DE10 $\mathrm{min}$ ), and level of medication dissolved following $4 \mathrm{~min}$ (DD4 min) were estimated for all plans as showed in table.

Table 4: Dissolution parameters for pilocarpine in pure, physically mixed and lyophilized form

\begin{tabular}{llll}
\hline Parameter & Pilocarpine & 1:1 corporal blend \pm SD & 1:1 lyophilized blend \pm SD* \\
\hline DD4 $\min (\%)$ & $41.23 \pm 2.14$ & $69.03 \pm 4.12$ & $89.23 \pm 2.56$ \\
DE10 $\min (\%)$ & 54.23 & 65.54 & $80.254 \pm 7.56$ \\
\hline
\end{tabular}

Note: *mean $\pm \mathrm{SD}(\mathrm{n}=3)$, DD= Drug dissolved, DE= Dissolution efficiency

There were critical contrasts in dissolution profiles for unadulterated medication, corporal blend, and lyophilized blend. Accounting DE10 min esteems, dissolution pace for Pilocarpine was expanded in the request: unadulterated medication less than 1:1 corporal blend less than 1:1 lyophilized blend proposing that dissolution flow is affected by lyophilization technique used to set up incorporation complex [24]. Following $4 \mathrm{~min}$, the level of unadulterated medication broken down was $41.23 \%$ in any case, the rate medicates dissolution from the physical blend, lyophilized complex was $69.03 \%$, and $89.23 \%$ individually.

\section{Orally disintegrating tablets characterization and evaluation}

Tablet definitions are set up as indicated by the planning framework that appeared in fig.; dependent on formulae referenced in fig. 5. Pilocarpine orally disintegrating tablets property for example, weight, thickness, friability, wetting period and water assimilation proportion, and medication content consistency were appeared [25]. Tablet plans met those prerequisites in terms of weight variance, thickness, friability, wetting period, and water assimilation proportion. Medication contents consistency ran from $97.3 \%$ to $103.7 \%$ and was inside the worthy limits. As shown in table 5, formulation F2 is having a medium concentration of MCC, whereas formulations F6, F7, F12 without MCC replicates more wetting time as compared to other formulations. Similarly, for water absorptions ratios, F1, F3, and F8 are having higher MCC concentrations and F6, F7, and F12 are without MCC concentrations.

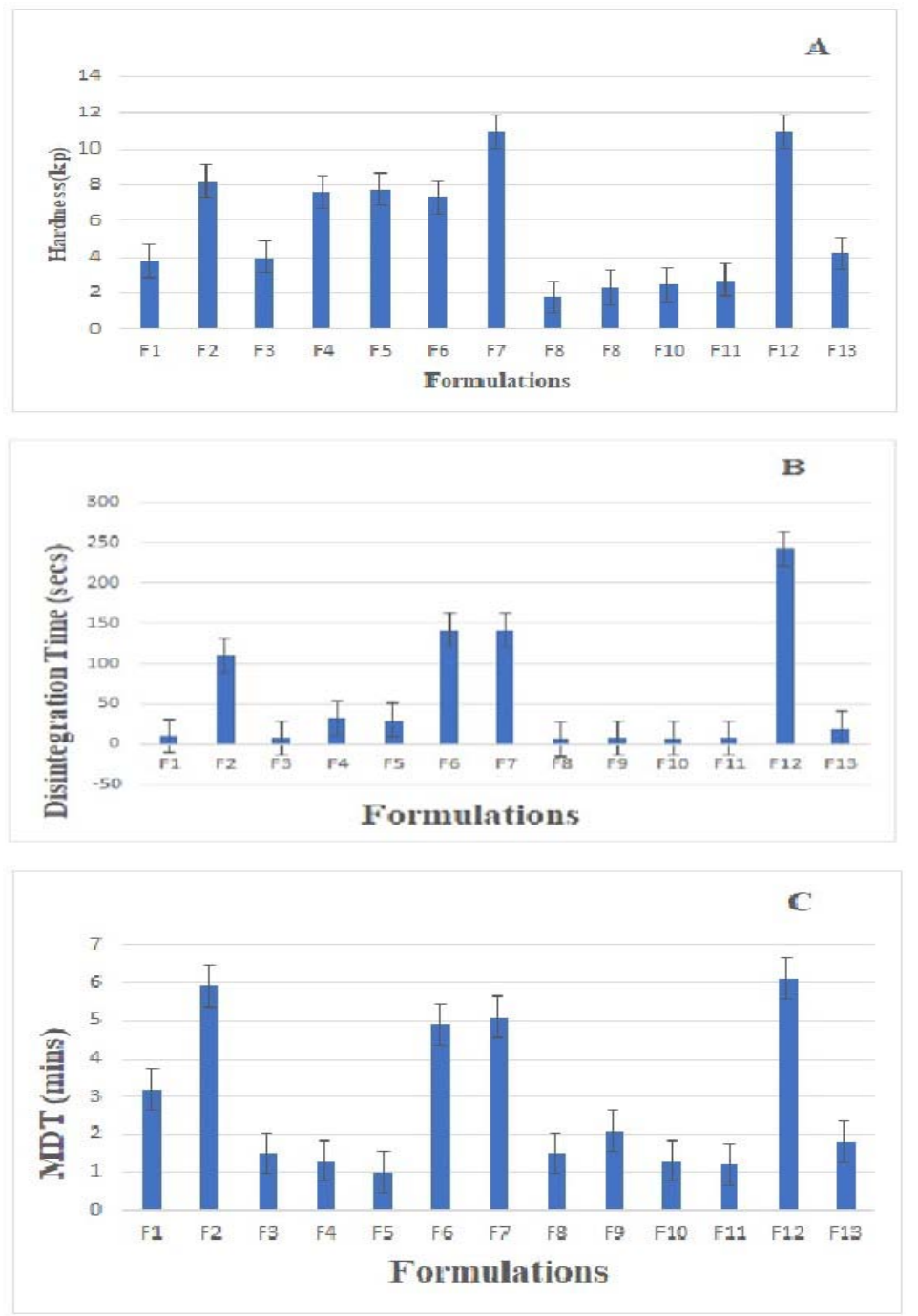

Fig. 5 (A-C): Effect of formulation factors on characteristic response variables of Pilocarpine *mean \pm SD (n=3) 
Table 5: Pilocarpine analysis for each experimental run

\begin{tabular}{|c|c|c|c|c|c|c|c|}
\hline \multirow[t]{2}{*}{ Formulations } & \multirow[t]{2}{*}{ Weight } & \multirow[t]{2}{*}{ Thickness } & \multirow[t]{2}{*}{ Wetting time } & \multirow{2}{*}{$\begin{array}{l}\text { Water } \\
\text { absorption ratio }\end{array}$} & \multirow{2}{*}{$\begin{array}{l}\text { Friability } \\
\text { (\%) }\end{array}$} & \multicolumn{2}{|c|}{ Drug content uniformity } \\
\hline & & & & & & Percentage & RSD \\
\hline F1 & $200.83 \pm 4.41$ & $3.28 \pm 0.012$ & $4.40 \pm 0.49$ & $105.78 \pm 5.60$ & 0.928 & 101.98 & 2.58 \\
\hline F2 & $201.87 \pm 3.35$ & $2.48 \pm 0.011$ & $133.15 \pm 7.41$ & $58.22 \pm 8.5$ & 0.103 & 100.64 & 2.60 \\
\hline F3 & $200.51 \pm 2.24$ & $3.31 \pm 0.014$ & $4.19 \pm 0.25$ & $131.47 \pm 2.94$ & 0.964 & 100.89 & 1.15 \\
\hline F4 & $199.14 \pm 1.59$ & $2.54 \pm 0.006$ & $47.46 \pm 5.47$ & $56.34 \pm 14.05$ & 0.649 & 98.94 & 2.49 \\
\hline F5 & $200.41 \pm 3.24$ & $2.55 \pm 0.014$ & $51.49 \pm 2.79$ & $42.60 \pm 3.31$ & 0.569 & 102.91 & 1.90 \\
\hline F6 & $200.38 \pm 3.36$ & $2.41 \pm 0.018$ & $104.45 \pm 4.86$ & $17.11 \pm 1.96$ & 0.875 & 103.69 & 1.28 \\
\hline F7 & $201.08 \pm 4.70$ & $2.25 \pm 0.015$ & $131.26 \pm 8.68$ & $19.91 \pm 8.06$ & 0.599 & 98.85 & 1.19 \\
\hline F8 & $195.91 \pm 1.54$ & $3.92 \pm 0.015$ & $2.40 \pm 0.38$ & $156.45 \pm 9.30$ & 1.060 & 97.29 & 0.94 \\
\hline F9 & $201.87 \pm 3.70$ & $3.19 \pm 0.011$ & $5.40 \pm 1.15$ & $80.12 \pm 3.92$ & 0.540 & 99.39 & 2.29 \\
\hline F10 & $197.35 \pm 2.34$ & $3.21 \pm 0.006$ & $7.02 \pm 0.48$ & $96.94 \pm 3.02$ & 0.961 & 98.74 & 2.90 \\
\hline F11 & $201.87 \pm 3.74$ & $3.21 \pm 0.080$ & $11.64 \pm 3.93$ & $84.53 \pm 3.41$ & 0.523 & 100.71 & 2.86 \\
\hline F12 & $201.82 \pm 2.26$ & $2.26 \pm 0.018$ & $214.27 \pm 7.41$ & $18.39 \pm 5.98$ & 0.352 & 100.92 & 2.74 \\
\hline F13 & $201.41 \pm 3.31$ & $2.91 \pm 0.014$ & $18.12 \pm 3.17$ & $75.25 \pm 7.54$ & 0.660 & 102.45 & 1.07 \\
\hline
\end{tabular}

Note: RSD: Relative Standard Deviation, mean \pm SD $(n=3)$

In fig. 5(A) and table 6, formulation with low croscarmellose sodium concentration and without MCC and formulation without CCS and MCC were found to have maximum hardness when compressed into tablets. Mannitol was used as a filler and these formulations had high concentrations of mannitol due to the absence of CCS and MCC.

In fig. 5(B) and table 6, Formulations F2, in the absence of CCS showed an increase in disintegration time. Formulation F6 and F7, in the absence of MCC, showed similar effects. Besides, the formulation F12 (in the absence of both MCC and CCS) also increased the disintegration time. This reflects that the concentration of croscarmellose sodium and microcrystalline cellulose combined or alone has a strong influence on the disintegration time. Formulation,
F1 with a high concentration of MCC and an absence of CCS, showed a disintegration time within one minute. This can be attributed to the disintegrant properties of MCC at higher concentrations. All other formulations in the presence of CCS and MCC showed disintegration of tablets within one minute.

The design of experiments (DoE) is embraced to upgrade basic detailing factors dependent on its impact on trademark reactions that influence presentation for orally crumbling tablets. Trademark reactions incorporate tablet Hardness, breaking downtime, and Mean Disintegration Time. The investigation shows that tablet hardness of $4.3 \mathrm{~N}$, breaking downtime of $12 \mathrm{sec}$, and mean disintegration time is $1.562 \mathrm{~min}$ [26].

Table 6: Results of face-centered CCD Experiments

\begin{tabular}{|c|c|c|c|c|c|}
\hline Formulations & $\begin{array}{l}\text { Croscarmellose } \\
\text { sodium (mg) }\end{array}$ & $\begin{array}{l}\text { MCC } \\
\text { (mg) }\end{array}$ & $\begin{array}{l}\text { Tablet } \\
\text { hardness-Y1 (kp } \pm S D)\end{array}$ & $\begin{array}{l}\text { Disintegration } \\
\text { time-Y2 (sec } \pm \text { SD) }\end{array}$ & $\begin{array}{l}\text { MDT-Y3 } \\
\text { (min) }\end{array}$ \\
\hline F1 & 0 & 120 & $3.98 \pm 0.25$ & $10.56 \pm 1.58$ & 3.19 \\
\hline $\mathrm{F} 2$ & 0 & 60 & $8.14 \pm 0.68$ & $105.41 \pm 3.58$ & 5.93 \\
\hline F3 & 6 & 120 & $3.99 \pm 0.31$ & $9.86 \pm 5.25$ & 1.54 \\
\hline F4 & 6 & 60 & $7.55 \pm 0.22$ & $34.14 \pm 2.18$ & 1.33 \\
\hline F5 & 6 & 60 & $7.89 \pm 0.23$ & $30.16 \pm 0.54$ & 1.02 \\
\hline F6 & 6 & 0 & $6.97 \pm 0.69$ & $130.47 \pm 3.74$ & 4.88 \\
\hline F7 & 12 & 0 & $11.09 \pm 0.75$ & $131.41 \pm 2.74$ & 5.16 \\
\hline F8 & 12 & 120 & $1.94 \pm 0.45$ & $5.42 \pm 2.12$ & 1.54 \\
\hline F9 & 6 & 60 & $2.18 \pm 0.89$ & $12.43 \pm 3.16$ & 2.14 \\
\hline F10 & 12 & 60 & $2.26 \pm 0.68$ & $10.26 \pm 1.54$ & 1.36 \\
\hline F11 & 6 & 60 & $2.58 \pm 0.61$ & $14.12 \pm 3.48$ & 1.28 \\
\hline F12 & 0 & 0 & $10.93 \pm 0.76$ & $242.15 \pm 1.33$ & 6.10 \\
\hline F13 & 6 & 60 & $4.32 \pm 0.49$ & $18.80 \pm 1.83$ & 1.57 \\
\hline
\end{tabular}

Note: *MCC: Microcrystalline Cellulose *MDT: Mean Disintegrating time *mean \pm SD $(n=3)$

Table 7: ANOVA for tablet hardness (Y1), disintegration time (Y2) and mean dissolution time (Y3)

\begin{tabular}{|c|c|c|c|c|c|c|c|c|c|c|c|c|}
\hline \multirow[t]{2}{*}{ Source } & \multicolumn{3}{|c|}{ Sum of Squares } & \multicolumn{3}{|c|}{$\begin{array}{l}\text { Degree of } \\
\text { freedom }\end{array}$} & \multicolumn{3}{|c|}{ F value } & \multicolumn{3}{|c|}{ p-value Prob $>F$} \\
\hline & Y1 & Y2 & Y3 & Y1 & Y2 & Y3 & Y1 & Y2 & Y3 & Y1 & Y2 & Y3 \\
\hline Model & 71.12 & 61451.15 & 35.14 & 2 & 7 & 5 & 7.56 & 114.25 & 11.20 & $0.0106^{*}$ & $0.0001^{*}$ & $0.0041^{*}$ \\
\hline X1-CSS & 12.45 & 4598.58 & 9.65 & 1 & 1 & 1 & 2.45 & 60.54 & 14.99 & 0.1222 & $0.0004^{*}$ & $0.0061^{*}$ \\
\hline X2-MCC & 56.45 & 7594.15 & 11.25 & 1 & 1 & 1 & 10.98 & 102.25 & 18.14 & $0.0061 *$ & $0.0019 *$ & $0.0042^{*}$ \\
\hline X1X2 & - & 1689.79 & 0.11 & - & 1 & 1 & - & 21.89 & 0.19 & - & $0.0046^{*}$ & 0.6785 \\
\hline $\mathrm{X}_{1}^{2}$ & - & 2996.14 & 7.01 & - & 1 & 1 & - & 38.96 & 11.30 & - & $0.0013^{*}$ & $0.0149 *$ \\
\hline $\mathrm{X}_{2}{ }^{2}$ & - & 5792.96 & 1.45 & - & 1 & 1 & - & 76.49 & 2.98 & - & $0.0003^{*}$ & $0.1598^{*}$ \\
\hline $\mathrm{X}_{1}^{2} \mathrm{X} 2$ & - & 906.39 & - & - & 1 & - & - & 10.47 & - & - & $0.0166^{*}$ & - \\
\hline $\mathrm{X} 1 \mathrm{X}_{2}{ }^{2}$ & - & 746.95 & - & - & 1 & - & - & 09.91 & - & - & $0.0220 *$ & - \\
\hline Residual & 47.25 & 358.48 & 4.36 & 10 & 5 & 7 & - & - & - & - & - & - \\
\hline Lack of Fit & 24.14 & 106.84 & 4.35 & 6 & 1 & 3 & 0.65 & 1.48 & 547.12 & 0.6458 & 0.2658 & $0.0001^{*}$ \\
\hline Pure Error & 22.45 & 241.15 & 0.112 & 4 & 4 & 4 & - & - & - & - & - & - \\
\hline Cor total & 120.48 & 60956.56 & 40.15 & 12 & 12 & 12 & - & - & - & - & - & - \\
\hline
\end{tabular}

Note: *Represents significant model terms with P-value $<0.05$ 


\section{Mathematical modeling of data obtained from experimental design}

Thirteen experiments were held to design the concentration of croscarmellose sodium $\left(\mathrm{X}_{1}\right)$ and microcrystalline cellulose $\left(\mathrm{X}_{2}\right)$ on the tablet hardness $\left(\mathrm{Y}_{1}\right)$, disintegration time $\left(\mathrm{Y}_{2}\right)$, and mean dissolution time $\left(Y_{3}\right)$ [17]. Data for the CCD runs are presented in table 6. The measured responses are illustrated in fig. $5(\mathrm{a}-\mathrm{c})$ and show that a selected formulation factor has a strong bonding on the selected results.

ANOVA was done to explain the importance level and magnitude of the effects of process variables and interaction between the variables. The results confirm the adequacy of the model $(\mathrm{P}<0.05)$ as shown in table 7. The model depicts the important factors $\left(X_{1}\right.$ and $\left.X_{2}\right)$ that affect the responses $\left(Y_{1}, Y_{2}\right.$, and $\left.Y_{3}\right)$ of Pilocarpine. The hardness of the tablet, concentration of microcrystalline cellulose (MCC) was important; however, the concentration of croscarmellose sodium (CCS) was not important. In disintegration times and mean dissolution times for ODTs, the concentration of both CCS and MCC were important. The interaction between the main variables (X1X2) was important for disintegration time $\left(\mathrm{Y}_{2}\right)$; however, the interaction between MCC and CCS were not important for tablet hardness $\left(\mathrm{Y}_{1}\right)$ and MDT $\left(\mathrm{Y}_{3}\right)$

The opposing impacts of $\mathrm{X}_{1}$ and $\mathrm{X}_{2}$ were minor as for tablet hardness $\left(\mathrm{Y}_{1}\right)$ and mean disintegration time (MDT) $\left(\mathrm{Y}_{3}\right)$ when contrasted with deterioration time $\left(\mathrm{Y}_{2}\right)$. The association impact somewhere in the range of $X_{1}$ and $X_{2}$ and quadratic impacts were minor regarding (MDT) $\left(\mathrm{Y}_{3}\right)$ when contrasted with breaking downtime $\left(\mathrm{Y}_{2}\right)$.

\section{CONCLUSION}

The Oral Disintegrating Tablets plan of Pilocarpine was prepared. Lyophilized incorporation composite for Pilocarpine and 2-HP $\beta C D$ improve disintegration amount and demonstrated capacity for covering of harsh flavor for medication that is essential of readiness for oral breaking down tablet as application. Flavor veiling capacity and system for incorporation composite as suggested dependent on the portrayal of the lyophilized consideration complex powder utilizing as extreme portrayal apparatus. Pilocarpine orally disintegrating tablets were effectively arranged utilizing the Pilocarpine-2-Hydroxy propyl $\beta$-cyclodextrin lyophilized composite powder. Few parts which influence the property of Pilocarpine Oral Disintegrating Tablets are arranged by consideration composite. Arrangement for diluents and super disintegrants enhanced the utilizing reaction surface approach with the focal composite structure to acquire fast disintegration and crumbling with adequate tablet parameters which improved medication ingestion for Oral Disintegrating Tablets in oral mucosa delivering quick alleviation from dry mouth, at last bringing about improved patient adherence and comfort.

\section{FUNDING}

Nil

\section{AUTHORS CONTRIBUTIONS}

All authors have contributed equally.

\section{CONFLICT OF INTERESTS}

The author has no conflict of interest to declare.

\section{REFERENCES}

1. Menella JA, Beauchamp GK. Modification of bitter taste in children. Dev Psychobiol 2009;43:120-7.

2. Mennella JA, Beauchamp GK. Optimizing oral medications for children. Clin Ther 2008;30:2120-32.

3. Nunn T, Williams J. Formulation of medicines for children. Br J Clin Pharmacol 2005;59:674-6.

4. Meyerhof W, Behrens M, Brockhoff A, Bufe B, Kuhn C. Human bitter taste perception. Chem Senses 2005;30 Suppl:21-3.
5. Purnamasari NAD, Saputra PA. Evaluation of orally disintegrating tablet of ibuprofen- $\beta$-cyclodextrin inclusion complex. Int J Appl Pharm 2020;12:60-4.

6. Sharma S, Lewis S. Taste masking technologies: a review. Int J Pharm Pharm Sci 2010;2:6-13.

7. Marchi N, Batra A, Tuxhorn I, Granata T, de Curtis M, Janigro D. Inflammation: cerebrovascular diseases, seizures, and epilepsy. Encycl Basic Epilepsy Res 2009;11:574-84.

8. Veiga F, Teixeira Dias JJC, Kedzierewicz F, Sousa A, Maincent P. Inclusion complexation of tolbutamide with $\beta$-cyclodextrin and hydroxypropyl- $\beta$-cyclodextrin. Int J Pharm 1996;129:63-71.

9. Ernest TB, Elder DP, Martini LG, Roberts M, Ford JL. Developing paediatric medicines: identifying the needs and recognizing the challenges. J Pharm Pharmacol 2007;59:1043-55.

10. Sana S, Rajani A, Sumedha N, Mahesh B. Formulation and evaluation of taste masked oral suspension of dextromethorphan hydrobromide. Int J Drug Dev Res 2012;4:159-72.

11. Khan MS, Vishakante GD, Bathool A. Development and characterization of pilocarpine loaded Eudragit nanosuspensions for ocular drug delivery. J Biomed Nanotechnol 2013;9:124-31.

12. Zingone G, Rubessa F. Preformulation study of the inclusion complex warfarin- $\beta$-cyclodextrin. Int J Pharm 2005;291:3-10.

13. Coates J. Interpretation of infrared spectra, a practical approach. Encycl Anal Chem; 2006. p. 1-23.

14. Patel R, Purohit N. Physico-chemical characterization and in vitro dissolution assessment of clonazepam-cyclodextrins inclusion compounds. AAPS PharmSciTech 2009;10:1301-12.

15. Copeland KAF. Applied linear statistical models. J Quality Technol; 1997. p. 233-3.

16. Badawy SIF, Shah KR, Surapaneni MS, Szemraj MM, Hussain M. Effect of spray-dried mannitol on the performance of microcrystalline cellulose-based wet granulated tablet formulation. Pharm Dev Technol 2010;15:339-45.

17. Thoorens G, Krier F, Leclercq B, Carlin B, Evrard B. Microcrystalline cellulose, a direct compression binder in a quality by design environment-a review. Int J Pharm 2014;473:64-72.

18. C SS. Formulation and evaluation of dextromethorphan hydrobromide controlled release hollow microspheres using natural polymer. Indones J Pharm 2014;25:181.

19. Ahmed SM, Abdel Rahman AA, Saleh SI, Ahmed MO. Comparative dissolution characteristics of bropirimine- $\beta$ cyclodextrin inclusion complex and its solid dispersion with PEG 6000. Int J Pharm 1993;96:5-11

20. Giunta AA, Wojtkiewicz SF, Eldred MS. Overview of modern design of experiments methods for computational simulations. Aerosp Sci Meet Exhib 2003.

21. Waleczek KJ, Cabral Marques HM, Hempel B, Schmidt PC. Phase solubility studies of pure (-)- $\alpha$-bisabolol and camomile essential oil with $\beta$-cyclodextrin. Eur J Pharm Biopharm 2003;55:247-51.

22. Malladi M, Jukanti R, Nair R, Wagh S, Padakanti H, Mateti A. Design and evaluation of taste masked dextromethorphan hydrobromide oral disintegrating tablets. Acta Pharm 2010;60:267-80.

23. Sunil J. Pharmaceutical Dosage Forms: Tablets. J of Pharm Sci; 1990. p. 1043.

24. Tiwari R, Srivastava B, Tiwari G, Rai A. Extended release promethazine $\mathrm{HCl}$ using acrylic polymers by freeze-drying and spray-drying techniques: formulation considerations. Brazilian J Pharm Sci 2009;45:829-40.

25. Tripathi A, Parmar D, Patel U, Patel G, Daslaniya D, Bhimani B. Taste masking: a novel approach for bitter and obnoxious drugs. J Pharm Sci Biosci Res 2011;1:136-42.

26. Singh B, Chakkal SK, Ahuja N. Formulation and optimization of controlled release mucoadhesive tablets of atenolol using response surface methodology. AAPS PharmSciTech 2006;7:1-10. 